\title{
RESEARCH ON THE SMARTPHONE FAST GROWING IMPACT ON MOBILE GAMING INDUSTRY IN CHINA
}

DOI: 10.17261/Pressacademia.2016.341

\author{
Boubacar Gamatche Abdoul Aziz ${ }^{1}$, Shen Lei ${ }^{2}$ \\ ${ }^{1}$ Donghua University. azzgam@hotmail.com \\ ${ }^{2}$ Donghua University
}

\begin{abstract}
Nowadays the smartphone industry becomes one of the most lucrative as well as fast-growing businesses, examining the impact on mobile game business of in China. The mobile game industry is growing fast and become the daily activities for mobile users. Due to rapid diffusion of mobile phones all over the world, the mobile game holds a number of exciting possibilities for new business models and growth strategies. In the present research we are trying to figure out the keys elements of the smartphone growing for mobile game business Industry. The research attempts to review on the salient issues of consumer behaviour of mobile gaming (CBMG), We propose a research model that examines why game players actively engage in playing mobile games, and how such engagement can affect their behavior in smartphone choice. Research has been conducted using informal interview, questionnaire, and wechat survey based on question develop by researcher. The respondents consist of 132 targeted participants which involves university students, housewives, and random public at various places. The result indicates that the smartphone fast growing has given the positive impact to the mobile game business which can help to develop business success.
\end{abstract}

Keywords: Smartphone, technology, mgaming, consumers behaviour, intention, players, China.

JEL Classification: M10, M31, D70

\section{INTRODUCTION}

As nowadays technology changes the world business and more significant than ever before that becomes a big impact of many firm's abilities to be responsive and market preventive. Information and innovation has turn out to be the key asset of most businesses. New technology may influence and have negative or positive impact on many running businesses. Most of selling business becomes online activities, much easier and simpler ever than traditional time. The aims of people who tend to participate or involve in online business entrepreneur is to gain profit. Nonetheless they must ensure that their product is well known and recognize by the consumers. The online business was launched by the internet as an innovative means of doing business in addition to making a profit. Since that all entrepreneurs persist to discover ways to make use of the internet for their business purposes. Dissemination information of the product and goods is significantly helping the business and promote or update their product. The innovation competition for new technology especially in the mobile phone becomes no barrier and hand phone is no longer just a device to make call and sending message. It has been upgraded to become smarter and sophisticated with multi-function and application and the name also has changed to become „smartphone. "based on Jyoti, Sutee and Efpraxia (2014), we considering a Smartphone as a mobile device that allows users to make telephone calls, sends and receives emails, downloads files, provides an internet connection and uses applications. Nowadays Smartphone application change lots the mobile game business by offering more benefits and before. Not with standing, the universality of smartphone application has becoming as a business and consumers" preferences as a way of interactive communication. The objective of this paper is to focus on the keys points from the use of smartphone application: mobile games on the smartphone business and to identify how it can assist in the mobile gaming business to be developed successfully. 


\section{THE PROBLEM STATEMENT}

Technology and Productivity are change in creating the unusual increases in measurement all the world. Productivity is one of the most closely watched indicators of long-term economic prospects. By rising productivity is the key to making possible permanent increases in the standard of living. The new technologies have led to studies and research to find possible approach in the mobile gaming. The Smartphones is one of the pivotal roles in modern technology invention. The smartphones are used as a means of communication since the social media plays a big role in socialization, especially through mobile gaming; there is a need to extend that social aspect into inclusive situation of business opportunity. The indulgent of mobile game business has been introduced in different ways and some ways have not been appropriate due to some factors affecting the mobile game in one way and another way infect the smartphone growth. Therefore, there is a need of introducing solid solution in smartphones application such as mobile game to enhance smartphones business opportunity. In this research in order to evaluate how the smartphone fast growing impact on mobile gaming industry in China, we are to answer the following question:

1. Is there any keys impact on the smartphone application such as mobile business on the mobile games growing?

2. Is the smartphone application such as mobile game can help the mobile business to develop successful?

\section{LITERATURE REVIEW}

Nowadays mobile technology is fast growing because of applications in daily business and have impact on brand awareness, divertissement, build relationships and grow your business such as text message advertising, create a smartphone App, make your website smartphone compatible, engage mobile customers through social networks or mobile game. All those functions are relative to the mobile application; to the point of dissimilar categories of business enable an assortment of requirements in the way of applications such as Google apps on android are above of the rivalry when it comes to smartphone applications. Many applications can be downloaded for free the purpose of doing businesses. Smartphones are become necessary to assist business to run well and more competent. That give the big push for operating system is an open source which has a variety of programs that any businessman can use to expand their business.

\subsection{Smartphone App's for Mobile Gaming Market}

In that growth and through that transition, smartphones as a gaming arena experienced its own evolution. More developers flocked to this medium, and the gaming sections of app stores became saturated. While mobile gaming apps using an up-front paid downloading model, wherein consumers paid a typically nominal fee to download an app, flourished in the early days of mobile gaming, the deluge of apps led to a change in monetization strategy. More apps started using the free-to-play model, wherein a consumer can download an app for free, and is then later monetized either via in-app purchases or in-app advertising. Since that transition, most consumers have been conditioned to expect quality mobile gaming apps for little or no cost. BI Intelligence reported the examination of how the mobile gaming market has been affected by the transition to F2P monetization. We also take a close look at how saturation in the mobile gaming category, combined with the standard F2P model, has led to numerous issues for developers, including spiking marketing costs, the premium on acquiring users who will spend heavily within a game (called whales), and the impact that it's having on mobile gamers who do not spend in-app. The report then identifies innovations in mobile app marketing and engagement that seek to alleviate the issues of F2P and inadequate monetization in the fact of mounting marketing costs.

- The mobile gaming app market is so big it makes other app categories seem small by comparison. Mobile gaming apps accounted for $20 \%$ of active apps in Apple's App Store in March 2016, according to AppsFlyer. That's more than double the second most popular category, business apps.

- It's only going to keep growing as quality smartphones become more accessible and more consumers look to their smartphones for gaming. In the US alone, 180.4 million consumers will play games on their mobile phones in 2016 , representing $56 \%$ of the population and a whopping $70 \%$ of all mobile 
phone users, according to estimates from eMarketer.

- This quick growth is resulting in numerous growing pains. Saturation in the market has led to the dominance of the free-to-play monetization model, which in turn has led to sky-high marketing costs.

- As marketing costs for mobile gaming apps has skyrocketed, so has the tendency for apps to focus on the very small segment of players who spend money in-app. This has resulted in game mechanics that optimize the amount of money being spent by this small user group, which can often alienate the large swath of users who do not spend money in-app.

- There are numerous new solutions coming to market that offer developers and publishing houses a diverse selection of monetization models which combine in-app purchases with other methods.

\subsection{Asian Smartphone Market Outlook}

Asia has 1.2 billion mobile gamers and controls $55 \%$ of the $\$ 24.9$ billion in worldwide mobile games revenue. The "Big Three" of China, Japan and South Korea currently control $90 \%$ of the region's mobile earnings. With lots of opportunity in the major markets and emerging regions, the question becomes "How can western publishers tackle the Asian mobile games market?" (Super Data report, 2015). Mobile gaming is especially prevalent in Asia and is responsible for $47 \%$ of the region's digital gaming revenues versus $41 \%$ globally. Super Data's report provides insights on the Big Three and the emerging markets of India, Indonesia, Malaysia, Vietnam, Hong Kong and Singapore. The report also highlights player preferences in India's fast-growing mobile games market. Findings include that two thirds of mobile gamers play racing games, making them the country's top mobile genre, and that only $3 \%$ of the country's mobile gamers are age 45 or older.

Other key findings from what we should know about the Asian mobile market 2016 report include:

$>$ Japan is the world's largest mobile games market, with $\$ 6.2$ billion in 2015E revenue. Despite having fewer players than China or the U.S., Japan has the highest average mobile games spending of any major country.

> China has 785 million mobile gamers, $62 \%$ of Asia's total. Asia's second-biggest mobile games market is volume-driven, as China has the lowest conversion rates and average spending of the "Big Three."

$>$ India is Asia's fastest-growing mobile games market, with revenue more than doubling from \$416 million in 2015E to $\$ 1.2$ billion by $2018 \mathrm{E}$. India's mobile games market has ample room to expand as the country's smartphone penetration rate is still low and the country's payment infrastructure remains underdeveloped.

> Android controls $73 \%$ of China and Korea's combined mobile revenue. Google's operating system enjoys a large lead over iOS in both countries thanks to local brands like Xiaomi and Samsung utilizing the platform.

> Through 2018E, emerging markets will account for $46 \%$ of Asia's mobile games revenue increases. Revenue growth is slowing in China, Japan and South Korea growth as the countries' smartphone markets become saturated.

Figure1: "Big three" Asian mobile games Market repartition

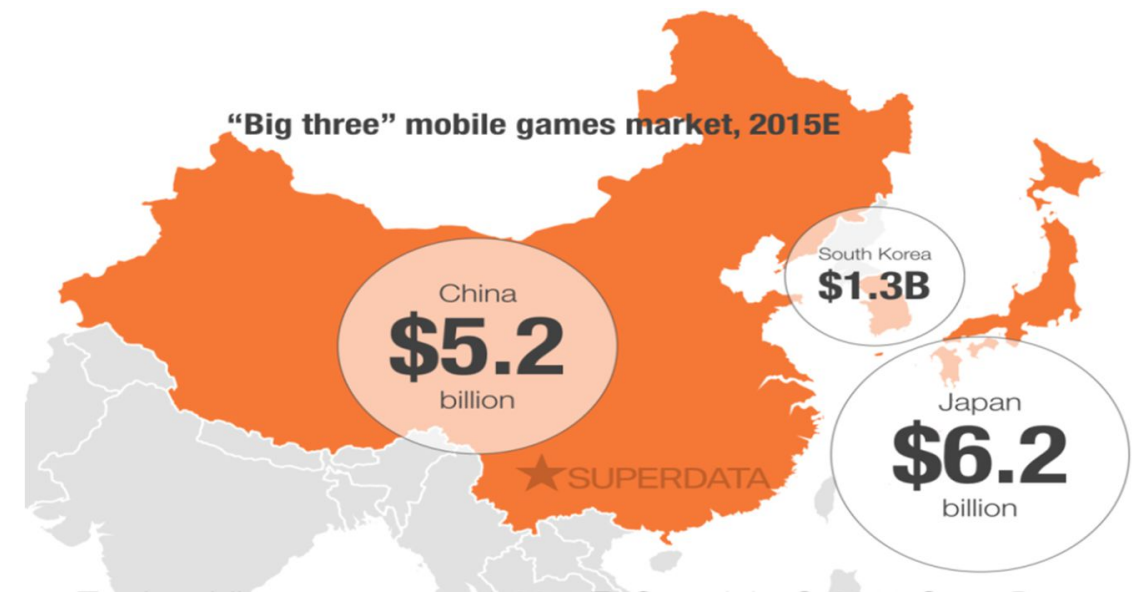




\subsection{Smartphone Phone Fast Growing and Gaming Review}

With consistent and remarkable economic growth over the past three decades, China has become a manufacturing powerhouse in the world (Holz, 2008). However, China's economic development has now reached a new stage that calls for different policies to promote future prosperity. In addition to policies highlighted in China's Twelfth Five-Year Plan, for example the stimulation of domestic demand and industrial restructuring, China has begun its quest for technological leadership through the promotion of indigenous innovation (Sigurdson, 2005; Suttmeier and Yao, 2004; Rowen and Hancock, 2008). Indeed, a few indigenous firms, such as Huawei and ZTE, have managed to catch up on technological ladder by taking advantage of the domestic market and the distinct feature of the technological regime in the telecommunications (switching system) industry (Mu and Lee, 2005). Liang and Yeh $(2011,188)$ define mobile game as "a video game played on mobile devices, including mobile phones, smart phones, PDA's or handheld computers". However, as handheld gaming has existed for such a long time in the form of Gameboys, Tetrises and other small devices, the phenomenon is not very new anymore. Smartphone become part of people's daily life and providing information to other people especially consumer where it can be considered as consumer information systems (CIS). According to Chun, Chung, and Shin (2013), "smartphone applications are developed by individuals, businesses, government agencies, the military, educational institutions, and any other organizations that want to use the technology to entertain, solve a problem, and fulfill a need". There are several types of communication apps in smartphones which are message and e-mail clients, a platform for clients to do networking which function as a medium to communicate with their consumers. App stores are providing so many applications for smartphone and are gaining popularity to surf for info among the people and it is no longer focusing on large national companies but local businesses, organizations and non-profits are finding successful ways to provide information or engage in sales and marketing activities using mobile content. Although the business can see on the desktop website, but it is more effective when the businesses engage with the viewer on the mobile website. For online business nowadays, any marketing advertising for the product can directly be promoted to all customers since they use their smartphones all the time. Customers can view their online shopping products online and purchase them from their smartphone applications.

Hwang (2012), mentioned that, people used to download application on their smartphones, and it shows how people are depending on these gadgets. Hwang mentioned that, the innovative technology via smartphones application may help the business to expand their product all over the world. Social networking is made easy at just one's fingertips to promote while taking and receiving order from customers around the world. It is a fact that smartphones may overtake desktop computers for personal use because of the expansion of the application which is growing rapidly among the smartphone users. With the sophisticated features on smartphones, they attract entrepreneurs particularly those who have the interest in the online business. The features and the functions of the smart phone itself help to represent the new frontier via the Internet and World Wide Web to advertise their product. Therefore, mobile app enables an online business to plan and focus on their sales growth. Karrigan (2011) has claimed that "Nearly 50 percent of Techno Metrica survey respondents believe they have been able to spend more time on growing business revenues due to their use of mobile apps. Fifty-one percent of these small businesses say their firms are more competitive". (p.3). Therefore, online business also can be categorized as small business, owners mostly have crucial of time in expanding their business, therefore by using smartphone applications, they can be increasing their sales and revenue and at the same time they also can use it on the administrative functions. Furthermore, mobile gaming businessmen also see the smartphone as an opportunity for their business use. They are currently using the internet as their most valuable tool through creative innovation of advertisement on the product and the emergence of the $4 \mathrm{G}$ network will speed up adoption because of newer devices, faster speed, enhanced and more effective mobile apps that allow businesses to communicate with the public. Advertisers believe that people are more likely to click on an advertisement that targets to their specific interests. Businesses owners are encouraged to produce alternate versions that provide beneficial functions in order to gain profit. As claimed by Kirk (2011) "the app is basically given away or offered at a very low price and users of the app are exposed to advertising messages". The interactive advertising on mobile is expected to grow due to no charges being imposed on them whenever they try to promote their selling items. If the users of the app are in the right demographic profile or represent a good match between a producer's product or service and their target 
market, this path can lead to higher profitability as well as the funding necessary to maintain and expand the business. Lu et al. (2007), who studied whether a TAM-based model is applicable in the Chinese context. Qi et al. (2009) also sought to expand the original TAM to take into account China-specific factors. The strength of the smartphone apps definitely provides entrepreneurial opportunities in this new generation of technology. Currently the research on mobile industry and mobile gaming in East Asia or China has largely consisted of studies on the factors affecting mobile services adoption (Liu \& Li 2010; 2011; Lu et al. 2008; Qi et al. 2009, for example). On the other hand, some studies have also tackled the issue of loyalty (Deng et al. 2010; Zhou et al.2010). These opportunities however, like most other entrepreneurial opportunities require a sound business plan and which can be considered as part of business career. Far more than a little programming goes into making an app successful, a careful planning must be undertaken to identify opportunities and develop products that offer competitive advantages.

\section{RESEARCH METHODOLOGY}

We conducted an experimental research method by using a Pearson correlation coefficient statistical measurements have been used to study how business work with new technology in today's world. In order to collect generalizable data that represent the whole population from the samples, questionnaire, verbal interview and wechat survey had been distributed specifically to smartphone user as the specify group. Wechat survey was by Wechat and email: the wechat survey and questionnaire link was sent via short message and by email for some companies which are private sector as well as government sector to study their behavior in using smartphone to do mobile gaming, and for verbal interview it is conducted in the open environment by the researcher. The questionnaire and survey consisted combination of 19 questions with mix open ended, close ended and likert scale question and grouped into three respective parts which are demographic section of participants which includes basic information regarding respondents such as the gender of the participants, age and status. The second part focused on the experience of mobile gaming using smartphone and the last part is participant's satisfaction which has been rated by the respondent based on Likert scale question. Two different approaches were used which are verbal interview based on the questionnaire and wechat survey. For verbal interview we asked participants based on the questions stated in the questionnaire which consisted of 19 questions including open ended, close ended and Likert scale type, then we interpreted, rated, classified and grouped the different responses different results. For wechat survey, respondents received link by message and they needed to answer the same questions in the questionnaire and submit so we can receive the response online. In this paper, Table 1 shows the variable Demographic characteristics for the data collection carried for this study, the results of the questions about the information gathering habits, and the intention to play mobile games to get information about how the smartphone impact on mobile games consumption. The analyses show that out of total samples about $68.2 \%$ are male and $31.8 \%$ are female. $14.4 \%$ are below 20 . Table 2 shows the variable Smartphone characteristics factors for the data collection carried for this study. 
Table 1: Demographic Characteristics for the Data Collection Carried for This Study

\begin{tabular}{|c|c|c|}
\hline Variable & Frequency & $\%$ \\
\hline \multicolumn{3}{|c|}{ Age( Years) } \\
\hline $10-20$ & 19 & 14.4 \\
\hline $20-30$ & 78 & 59.1 \\
\hline $30-40$ & 29 & 22 \\
\hline 40- above & 6 & 4.5 \\
\hline Total & 132 & 100.0 \\
\hline \multicolumn{3}{|c|}{ Gender } \\
\hline Male & 90 & 68.2 \\
\hline Female & 42 & 31.8 \\
\hline Total & 132 & 100.0 \\
\hline \multicolumn{3}{|c|}{ Profession } \\
\hline Student & 93 & 70.5 \\
\hline Teacher & 16 & 12.1 \\
\hline Employee & 21 & 15.9 \\
\hline Other & 2 & 1.5 \\
\hline Total & 132 & 100.0 \\
\hline \multicolumn{3}{|c|}{ User Category } \\
\hline Expert & 46 & 34.8 \\
\hline Novice & 83 & 62.9 \\
\hline Total & 132 & 100.0 \\
\hline \multicolumn{3}{|c|}{ Education } \\
\hline Below Bachelor & 39 & 29.5 \\
\hline Bachelor & 47 & 35.6 \\
\hline Master & 29 & 22 \\
\hline Variable & Frequency & $\%$ \\
\hline \multicolumn{3}{|c|}{ Age( Years) } \\
\hline $10-20$ & 19 & 14.4 \\
\hline $20-30$ & 78 & 59.1 \\
\hline $30-40$ & 29 & 22 \\
\hline 40- above & 6 & 4.5 \\
\hline Total & 132 & 100.0 \\
\hline \multicolumn{3}{|c|}{ Gender } \\
\hline Male & 90 & 68.2 \\
\hline Female & 42 & 31.8 \\
\hline Total & 132 & 100.0 \\
\hline \multicolumn{3}{|c|}{ Profession } \\
\hline Student & 93 & 70.5 \\
\hline Teacher & 16 & 12.1 \\
\hline Employee & 21 & 15.9 \\
\hline Other & 2 & 1.5 \\
\hline Total & 132 & 100.0 \\
\hline \multicolumn{3}{|c|}{ User Category } \\
\hline Expert & 46 & 34.8 \\
\hline Novice & 83 & 62.9 \\
\hline Total & 132 & 100.0 \\
\hline \multicolumn{3}{|c|}{ Education } \\
\hline Below Bachelor & 39 & 29.5 \\
\hline Bachelor & 47 & 35.6 \\
\hline Master & 29 & 22 \\
\hline Ph.D & 17 & 12.9 \\
\hline Total & 132 & 100.0 \\
\hline
\end{tabular}


Table 2: Smartphone Characteristics for the Data Collection Carried for This Study

\begin{tabular}{|c|c|c|}
\hline Variable & Frequency & $\%$ \\
\hline \multicolumn{3}{|c|}{ Are you using a Smartphone? } \\
\hline Yes & 101 & 76.5 \\
\hline No & 31 & 23.5 \\
\hline Total & 132 & 100 \\
\hline \multicolumn{3}{|c|}{ Which Mobile Phone Generation you using? } \\
\hline Feature Phone & 7 & 5.3 \\
\hline $2 \mathrm{G}$ & 9 & 6.8 \\
\hline $3 G$ & 37 & 28 \\
\hline $4 G$ & 79 & 59.8 \\
\hline Total & 132 & 100 \\
\hline \multicolumn{3}{|c|}{ How long you are using that phone? } \\
\hline $0-1$ Year & 46 & 34.8 \\
\hline 1-2 Year & 33 & 25 \\
\hline 2-3 Year & 24 & 18.2 \\
\hline 3-4 Year & 5 & 3.8 \\
\hline 4-5 Year & 24 & 18.2 \\
\hline Total & 132 & 100 \\
\hline \multicolumn{3}{|c|}{ Did you constantly connect Internet? } \\
\hline Yes & 123 & 93.2 \\
\hline No & 9 & 6.8 \\
\hline Total & 132 & 100 \\
\hline \multicolumn{3}{|c|}{ Did you download Games on your mobile? } \\
\hline Yes & 87 & 65.9 \\
\hline No & 45 & 34.1 \\
\hline Total & 132 & 100 \\
\hline \multicolumn{3}{|c|}{ How do you download Games? } \\
\hline Apple stores & 84 & 63.6 \\
\hline Google play & 26 & 19.7 \\
\hline Others specify & 22 & 16.7 \\
\hline Total & 132 & 100 \\
\hline
\end{tabular}

\section{FINDINGS, ANALYSIS AND LIMITATION}

Using Pearson correlation coefficient with SPSS to evaluate the result of the product moment which was computed to assess the relationship between the frequent used of smartphone by people have accessibility and effectiveness of a mobile gaming promoted through smartphone application. There was a positive correlation between the two variables, $r=0.98, n=132, p=0.002$. Overall, there was a strong, positive correlation between smartphone user and the effectiveness of a mobile game through the new technology which is the smartphone.

Data collection was carried out between November 2015 and July 2016, the respondents of participants which involves in this study by answering the questions and survey as well as responding to the question asked by the researcher included university students, housewives, and random public at various places total sample size was 132 respondents. The average of mobile phone expenditure group dominates the sample (with average monthly expenditure less than $30 \mathrm{RMB}$ ). This is consistent with the high proportion of prepaid customers in China and those who spend more are likely to be using the technology for business rather than for personal use. In mobile applications dominated by functional applications users segment (47.7\%), followed by 
downloadable mobile games (40.4\%). This result aligns with reported results (Schiglick et al. 2004; Wisniewski \& Morton 2005). The mobile gamer sub-sample consisted of both female and male consumers (68525\% and $31.8 \%$ respectively). The possibility of an association between "gender and "playing" in the sample was tested and rejected (Pearson's Chi-Square 0.103 with a significance level of 0.749), meaning that both males and females were likely to be mobile gaming adopters. Segmentation of the data collect respondents $(11.3 \%$, males only) preferred strategy games and the same number (females only) preferred card games. Action and sports games were preferred by females and males (15.4\% and $24.1 \%$ ) with more females than males expressing the preference (the respective ratios were 3:2 and 3:1). Consistent with the proposed research model further analysis was performed on the mobile game sub-sample only (132 respondents). The construct validity of the instrument was evaluated by computing convergent and discriminate validity performing a principal component analysis with a Varimax rotation. Seven factors (EL, UF, EJ, Inf, Abs, Int, Freq, UC, Att) met the criteria used in the study (Hair et al., 1998, p. 90, p.111). Table 5 shows the Pearson's correlation result and can show the correlation is significative at 0.05 As a result, in the revised model two constructs (PCM and AT) were dropped. Using SPSS, a correlation bivariate procedure

Table 3 shows the correlation of the different factors affecting the smartphone and mobile gaming relation and was run including the factors retained in the revised model. Using Pearson's correlation (" $r$ ") as a measure of strength it was found that IU had a significantly strong relationship with $E L(r=1, \operatorname{sig} .=0.000), U F(r=$ 0. 446, sig. =0.000), ENJ $(r=0.410$, sig. =0.000), Infl $(r=0.226$, sig. $=0.009)$, and Abs $(r=0.453$, sig. $=0.000)$ Int $(r=0.273$, sig. $=0.002)$, Freq $(r=0.177$, sig. $=0.042), U C(r=-0.150$, sig. $=0.066)$, Att $(r=-0154$, sig. $=$ $0.078)$.

Table 3: Pearson's Correlation Results (correlation is significative at 0.05)

\begin{tabular}{|c|c|c|c|c|c|c|c|c|c|c|}
\hline & & $\begin{array}{l}\text { easy to } \\
\text { learn }\end{array}$ & useful & enjoy & influence & Absorbe & Intention & Frequently & $\begin{array}{c}\text { Use } \\
\text { context }\end{array}$ & $\begin{array}{c}\text { Attitu } \\
\text { de }\end{array}$ \\
\hline \multirow{3}{*}{$\begin{array}{l}\text { easy to } \\
\text { learn }\end{array}$} & Pearson Correlation & 1 & $.446^{* *}$ & $.410^{* *}$ & $.226^{* *}$ & $.453^{* *}$ & $.273^{* *}$ & $.177^{*}$ & -.160 & -.154 \\
\hline & Sig. (2-tailed) & & .000 & .000 & .009 & .000 & .002 & .042 & .066 & .078 \\
\hline & $\mathrm{N}$ & 132 & 132 & 132 & 132 & 132 & 132 & 132 & 132 & 132 \\
\hline \multirow[t]{3}{*}{ useful } & Pearson Correlation & $.446^{* *}$ & 1 & $.549^{* *}$ & $.317^{* *}$ & $.500^{* *}$ & $.465^{* *}$ & $.480^{* *}$ & -.054 & -.008 \\
\hline & Sig. (2-tailed) & .000 & & .000 & .000 & .000 & .000 & .000 & .538 & .930 \\
\hline & N & 132 & 132 & 132 & 132 & 132 & 132 & 132 & 132 & 132 \\
\hline \multirow[t]{3}{*}{ enjoyment } & Pearson Correlation & $.410^{* *}$ & $.549^{* *}$ & 1 & $.485^{* *}$ & $.535^{* *}$ & $.347^{* *}$ & $.290^{* *}$ & .018 & .007 \\
\hline & Sig. (2-tailed) & .000 & .000 & & .000 & .000 & .000 & .001 & .836 & .936 \\
\hline & N & 132 & 132 & 132 & 132 & 132 & 132 & 132 & 132 & 132 \\
\hline \multirow[t]{3}{*}{ influence } & Pearson Correlation & $.226^{* *}$ & $.317^{* *}$ & $.485^{* *}$ & 1 & $.419^{* *}$ & $.280^{* *}$ & $.362^{* *}$ & .051 & .068 \\
\hline & Sig. (2-tailed) & .009 & .000 & .000 & & .000 & .001 & .000 & .562 & .442 \\
\hline & $\mathrm{N}$ & 132 & 132 & 132 & 132 & 132 & 132 & 132 & 132 & 132 \\
\hline \multirow[t]{3}{*}{ Absorbe } & Pearson Correlation & $.453^{* *}$ & $.500^{* *}$ & $.535^{* *}$ & $.419^{* *}$ & 1 & $.445^{* *}$ & $.399^{* *}$ & -.070 & -.048 \\
\hline & Sig. (2-tailed) & .000 & .000 & .000 & .000 & & .000 & .000 & .426 & .582 \\
\hline & $\mathrm{N}$ & 132 & 132 & 132 & 132 & 132 & 132 & 132 & 132 & 132 \\
\hline \multirow[t]{3}{*}{ Intention } & Pearson Correlation & $.273^{* *}$ & $.465^{* *}$ & $.347^{* *}$ & $.280^{* *}$ & $.445^{* *}$ & 1 & $.653^{* *}$ & -.077 & -.043 \\
\hline & Sig. (2-tailed) & .002 & .000 & .000 & .001 & .000 & & .000 & .383 & .628 \\
\hline & $\mathrm{N}$ & 132 & 132 & 132 & 132 & 132 & 132 & 132 & 132 & 132 \\
\hline \multirow[t]{3}{*}{ Frequently } & Pearson Correlation & $.177^{*}$ & $.480^{* *}$ & $.290^{* *}$ & $.362^{* *}$ & $.399^{* *}$ & $.653^{* *}$ & 1 & .016 & -.045 \\
\hline & Sig. (2-tailed) & .042 & .000 & .001 & .000 & .000 & .000 & & .851 & .610 \\
\hline & $\mathrm{N}$ & 132 & 132 & 132 & 132 & 132 & 132 & 132 & 132 & 132 \\
\hline Use context & Pearson Correlation & -.160 & -.054 & .018 & .051 & -.070 & -.077 & .016 & 1 & $.347^{* *}$ \\
\hline
\end{tabular}




\begin{tabular}{|c|c|c|c|c|c|c|c|c|c|c|}
\hline & Sig. (2-tailed) & .066 & .538 & .836 & $\begin{array}{l}.562 \\
\end{array}$ & .426 & .383 & .851 & & .000 \\
\hline & $N$ & 132 & 132 & 132 & 132 & 132 & 132 & 132 & 132 & 132 \\
\hline \multirow[t]{3}{*}{ Attitude } & $\begin{array}{l}\text { Pearson } \\
\text { Correlation }\end{array}$ & -.154 & -.008 & .007 & .068 & -.048 & -.043 & -.045 & $.347^{* *}$ & 1 \\
\hline & Sig. (2-tailed) & .078 & .930 & .936 & .442 & .582 & .628 & .610 & .000 & \\
\hline & $N$ & 132 & 132 & 132 & 132 & 132 & 132 & 132 & 132 & 132 \\
\hline \multicolumn{4}{|c|}{$\begin{array}{l}\text { **. Correlation is significant at the } 0.01 \text { level (2- } \\
\text { tailed). }\end{array}$} & & & & & & & \\
\hline \multicolumn{4}{|c|}{$\begin{array}{l}\text { *. Correlation is significant at the } 0.05 \text { level }(2- \\
\text { tailed). }\end{array}$} & & & & & & & \\
\hline
\end{tabular}

Considering the both gender male and female from different age groups between 10 to $40+$ and covered different types of status such as housewives, university students, college student and public picked randomly at different places and time. The participants were also included locals and internationals. About $89 \%$ of the participant's responded to the wechat survey and another $11 \%$ responded through informal interviews conducted by the researcher. From an overall view of the collected response, almost $91 \%$ agreed that they have knowledge on certain products via online browsing. Just look around us, people are addicted to smartphone up to the point that they don't put much attention to their surroundings. For example, everywhere we go we can see how people are so attached to their mobile phones. Most of them are smartphone users who actively use smartphone to browse website, social networking, and get information about product through Facebook, WhatsApp group, play games and so on. Advertising business product by using new technology gives easy access especially which using smartphone as it is effective and applicable in today's world. Through this finding we also found that the result supported our purpose of the study which is to see how people can benefit from the usage of smartphone and their positive reactions towards this new technology especially in social application to businesses. Limitation of this research might include the region covered which the research was only held in a city and not include other parts of state as well as rural areas. 6. Conclusion Through this paper we have analyzed how smartphone business can affect the success of mobile game business. The result of the findings showed that new technology such as smartphone can help to develop business success and benefit mobile game business. The result which fully supports the objective of study it is shown that people are attached to smartphone so it is an advantage for business people to promote their product through this new technology to be more efficient and gain more profit for the business. Also, each smartphone is able to access to all applications provided where this allows business people to create their own application program to be used by consumer through which android operating system is an open source and has a variety of programs as anyone can develop for this device. The means of that is there are many mobile game applications can be download for free as well as many standard ones for sale via the App stores. Another benefit is that it can automatically sync with desktop computer which this is important to people who do business as they do not have to transfer data from smartphone to desktop in order to access as well as to record it. In addition, to increase brand awareness, building relationships and grow business by using smartphone as a new technology is an advanced way in how business capitalize on the strategic profit gain. Growing popularity of this new technology of smartphone can help in product promotion through text message advertising, create a smartphone application, and develop business of mobile game application. This application is compatible and accessible from smartphone and also by using social network to engage with mobile customer. The advantages for customer who do online shopping through their smartphone is they have plenty time to browse through and make comparison between products without any effort to bring computer or laptop and they just can browse through their smartphone. This can be the advanced step for business people to promote their product creatively using this medium and it is also important on how they convince the customer to buy their product by using this new technology of smartphone. In order for business people to survive in this rapidly advance new technological world which uses mobile technology and online revolution, 
businesses need to be innovative by bringing up their popular digital channels in store to help enhancing their customer experience and also creating a dynamic, exciting and vibrant environment for customers.

\section{CONCLUSION}

This article presented the research on the smartphone and impact on mobile gaming industry in China. The mobile phone and smartphone market has become more competitive, complex and connected over the past three years. Connected not just in terms of connectivity and sensor advancements, but the smartphone segment's interrelationship with other markets and business models. It is myopic to discuss the mobile phone and smartphone markets and their value creation, either directly or indirectly, in isolation, there are both benefits and drawbacks to this. Burgeoning ecosystems from the Web, a new wave of content and services and convergence with other established and emerging hardware segments are all affecting how value is created and extracted from the smartphone market. This has two fundamental consequences:

Firstly, it means that the smartphone market is as dynamic as ever and is far from the permanent two-horse race between Apple and Samsung that is depicted by some industry commentators. In addition, although an operating system duopoly exists between Android and iOS, fragmentation caused by Chinese government regulation and ecosystem growth on top of Android means the competitive significance of this duopoly is declining. Android's dominance does not translate directly into dominance for Google. The complexity of the smartphone market and its broader relationship with other technology segments and business models means change is likely to be abrupt and substantial.

Secondly, success in the smartphone market and the way in which value is extracted is fundamentally changing. This raises questions about which attributes will define success over the four years of our forecast period given the challenges facing an abundance of traditional mobile phone manufacturers. CCS Insight believes successful companies will ultimately conform to one or more of these profiles: The company has a broader business model such as advertising or retail that mobile extends and enriches thanks to its advantages of reach, engagement, context, connectivity and increasing affordability. Good examples are Amazon and Xiaomi; both supply hardware but margin is largely derived elsewhere. The company has a parallel business that reinforces the profit margin made on hardware. Increasingly this is in the realm of content and services. The best example here remains Apple but Samsung, Sony and others are striving to emulate Apple's success. The company enjoys substantial advantages of scale, supply chain and costs that enable it to compete profitably using a margin-based hardware model.

We believe Lenovo in particular is poised to challenge Samsung's dominance in this regard. These attributes are not mutually exclusive, nor will they characterise all players that participate in the smartphone market over the coming years. The low barriers to entry that have come to typify smartphone manufacturing means the long tail of manufacturers will continue to grow. However, this long tail will be characterised by extremely low margins for the majority. CCS Insight believes the attributes above will characterise those companies that extract the majority of the value, either directly or indirectly. Further change and disruption to the smartphone industry is highly likely over the forecast period. Samsung's dominance is set to come under growing pressure from the combined abundance of smaller Chinese players and new manufacturing challengers with mounting scale and cost advantages. Furthermore, the necessity for diversification will see Samsung face mounting competition from Web players from both East and West. This too will affect Apple: its successes in delivering content and services and in hardware integration will determine its progress and the speed at which it too feels growing pressure on profit margins.

\section{Acknowledgements}

The paper is based in part on an unpublished Ph. D dissertation (B. Gamatche Abdoulaziz, 2016). As the author, I would like to thank the reviewers for the helpful critique. 


\section{REFERENCES}

American Psychological Association. (1972). Ethical standards of psychologists. Washington, DC: American Psychological Association.

Anderson, C. A., Gentile, D. A., \& Buckley, K. E. (2007). Violent video game effects on children and adolescents: Theory, res earch and public policy. http://dx.doi.org/10.1093/acprof:oso/9780195309836.001.0001

Beck, C. A. J., \& Sales, B. D. (2001). Family mediation: Facts, myths, and future prospects (pp. 100-102). Washington, DC: American Psychological Association. http://dx.doi.org/10.1037/10401-000

Bernstein, T. M. (1965). The careful writer: A modern guide to English usage (2nd ed.). New York, NY: Atheneum.

Bjork, R. A. (1989). Retrieval inhibition as an adaptive mechanism in human memory. In H. L. Roediger III, \& F. I. M. Craik (Eds.), Varieties of memory \& consciousness (pp. 309-330). Hillsdale, NJ: Erlbaum.

Cress, C. M. (2009). Curricular strategies for student success and engaged learning [PowerPoint slides]. Retrieved from http://www.vtcampuscompact.org/2009/TCL_post/presenter_powerpoints /Christine\%20Cress\%20-\%20Curricular\%20Strategies.ppt

Driedger, S. D. (1998, April 20). After divorce. Maclean's, 111(16), 38-43.

Gibbs, J. T., \& Huang, L. N. (Eds.). (1991). Children of color: Psychological interventions with minority youth. San Francisco, CA: Jossey-Bass.

Gilbert, D. G., McClernon, J. F., Rabinovich, N. E., Sugai, C., Plath, L. C., Asgaard, G., ... Botros, N. (2004). Effects of quitting smoking on EEG activation and attention last for more than 31 days and are more severe with stress, dependence, DRD2 A 1 allele, and depressive traits. Nicotine and Tobacco Research, 6, 249-267. http://dx.doi.org/10.1 080/1462220041 0001676305

Goleman, D. (2009). What makes a leader? In D. Demers (Ed.), AHSC 230: Interpersonal communication and relationships (pp. 47-56). Montreal, Canada: Concordia University Bookstore. (Reprinted from Harvard Business Review, 76(6), pp. 93-102, 1998).

Guignon, C. B. (1998). Existentialism. In E. Craig (Ed.), Routledge encyclopedia of philosophy (Vol. 3, pp. 493-502). London, England: Routledge.

Healey, D. (2005). Attention deficit/hyperactivity disorder and creativity: An investigation into their relationship (Unpublished doctoral dissertation). University of Canterbury, Christchurch, New Zealand.

Herculano-Houzel, S., Collins, C. E., Wong, P., Kaas, J. H., \& Lent, R. (2008). The basic non uniformity of the cerebral cortex. Proceedings of the National Academy of Sciences, 105, 12593-12598. http://dx.doi.org/10.1073/pnas.0805417105

Klimoski, R., \& Palmer, S. (1993). The ADA and the hiring process in organizations. Consulting Psychology Journal: Practice and Research, 45(2), 10-36. http://dx.doi.org/10.1037/1061-4087.45.2.10

Kubrick, S. (Director). (1980). The Shining [Motion picture]. United States: Warner Brothers.

Liu, S. (2005, May). Defending against business crises with the help of intelligent agent based early warning solutions. Paper presented at the Seventh International Conference on Enterprise Information Systems, Miami, FL. Abstract retrieved from http://www.iceis.org/iceis2005/abstracts_2005.htm

MacIntyre, L. (Reporter). (2002, January 23). Scandal of the Century [Television series episode]. In H. Cashore (Producer), The fifth estate. Toronto, Canada: Canadian Broadcasting Corporation.

McLuhan, M. (1970a). Culture is our business. New York, NY: McGraw-Hill.

McLuhan, M. (1970b). From cliche to archetype. New York, NY: Viking Press.

Mellers, B. A. (2000). Choice and the relative pleasure of consequences. Psychological Bulletin, 126 , $910-924$. http://dx.doi.org/10.1037/0033-2909.126.6.910

Postman, N. (1979). Teaching as a conserving activity. New York, NY: Delacorte Press.

Postman, N. (1985). Amusing ourselves to death: Public discourse in the age of show business. New York, NY: Viking.

Semenak, S. (1995, December 28). Feeling right at home: Government residence eschews traditional rules. Montreal Gazette, p. A4.

Strong, E. K. Jr., \& Uhrbrock, R. S. (1923). Bibliography on job analysis. In L. Outhwaite (Series Ed.), Personnel Research Series: Vol. 1. Job analysis and the curriculum (pp. 140-146). http://dx.doi.org/10.1037/10762-000

http://superdata-research.myshopify.com/products/asian-mobile-market?variant=103335356 